\title{
Effect of resin content and pressing temperature on banana pseudo- stem particle boards properties using full factorial design
}

\author{
ANA D. BARRAGÀN-LUCAS ${ }^{1,2}$, CRISTHIAN LLERENA-MIRANDA ${ }^{2}$, MARIA FERNANDA QUIJANO-AVILÉS ${ }^{1}$, \\ IVÁN A. CHÓEZ-GUARANDA ${ }^{1}$, LINDA C. MALDONADO-GUERRERO ${ }^{3}$ and PATRICIA I. MANZANO-SANTANA ${ }^{1,4}$ \\ ${ }^{1}$ Centro de Investigaciones Biotecnológicas del Ecuador, Escuela Superior Politécnica del \\ Litoral, Campus Gustavo Galindo, P.O. Box 09-01-5863 Guayaquil, Ecuador \\ ${ }^{2}$ Escuela Superior Politécnica del Litoral, Facultad de Ciencias Naturales y Matemáticas, \\ Campus Gustavo Galindo, P.O. Box 09-01-5863 Guayaquil, Ecuador \\ ${ }^{3}$ Universidad Laica Vicente Rocafuerte, Av. de las Américas, P.O. Box 11-33 Guayaquil, Ecuador \\ ${ }^{4}$ Escuela Superior Politécnica del Litoral, Facultad de ciencias de la vida, Campus \\ Gustavo Galindo, P.O. Box 09-01-5863 Guayaquil, Ecuador
}

Manuscript received on March 5, 2018; accepted for publication on November 22, 2018

\begin{abstract}
How to cite: BARRAGAN-LUCAS AD, LLERENA-MIRANDA C, QUIJANO-AVILÈS MF, CHÒEZ-GUARANDA IA, MALDONADO-GUERRERO LC AND MANZANO-SANTANA PI. 2019. Effect of resin content and pressing temperature on banana pseudo-stem particle boards properties using full factorial design. An Acad Bras Cienc 91: e20180302. DOI 10.1590/0001-3765201920180302.
\end{abstract}

\begin{abstract}
The volume of global gross banana exports reached a record of 117.9 million tonnes in 2015 (FAO 2017), which agro-industrial wastes derived as the pseudo-stem, rachis and leaves do not have an industrial application instead they are discarded. This research study applies full factorial design and response surface methodology to determine the effect of pressing temperature and resin content on density (D), moisture (M), water absorption (WA), water swelling (WS), module of rupture (MOR), module of elasticity (MOE) and formaldehyde content (FC) of particle board made of banana pseudo-stem. A $2^{2}$ factorial design was performed, factors considered were resin and temperature. The low level of resin was $15 \%$ in the coarse fiber $(\mathrm{CF})$ and $35 \%$ in fine fiber (FF); high level as $25 \% \mathrm{CF}$ and $45 \% \mathrm{FF}$. Temperature levels were $150^{\circ} \mathrm{C}$ and $170^{\circ} \mathrm{C}$ respectively. The boards met all quality parameters except ones with low resin content that didn't meet WS parameter. Furthermore, resin affected positively on WA, FC and MOE, and decreased D, WS and MOR values. Meanwhile, temperature affected negatively on D, WS, and increased FC, WA, MOE, MOR properties; none of the factors affected $\mathrm{M}$ response. Process conditions were optimized to $162.61^{\circ} \mathrm{C}$ and $43.15 \% \mathrm{FF}, 23.97 \% \mathrm{CF}$.
\end{abstract}

Key words: fiber board, Musa paradisiaca, optimization, pseudo-stem, waste.

\section{INTRODUCTION}

Musa paradisiaca (banana) plant is manly cultivated in tropical and subtropical countries (Gabhane et al. 2014). Ecuador is the largest

Correspondence to: Ana Delida Barragán Lucas

E-mail: adbarrag@espol.edu.ec

ORCid: https://orcid.org/0000-0003-2318-5872 exporter of banana and provides $30 \%$ of the world supply. Approximately, 214.000 ha of land is under banana cultivation in Ecuador (PRO Ecuador 2015). Moreover, each hectare of banana cultivation generates approximately 220 tons of residual waste (Quintana et al. 2009). Thus, bunch, pseudo-stem and leaves are the main waste (Cassidy 
et al. 2014). However, that residual biomass is conformed principally by lignocellulosic material (Gabhane et al. 2014) that is discarded nears rivers and roads causing environmental problems (Shah et al. 2005).

Furthermore, the replacement of commercial wheat flour with $10 \%$ of banana pseudo-stem flour in the preparation of bread revealed that the composite bread had greater content of insoluble fiber, total dietary fiber, total phenolics and antioxidant properties than the control bread (Ho et al. 2013). Also, the adding of nanocellulose isolated from banana pseudo-stem improves the mechanical properties of polyvinyl alcohol films. As a matter of the fact, higher concentrations of nanocellulose increase water-vapor barrier of this kind of nanocomposite (Pereira et al. 2014). Additionally, recent research proposed to use banana waste to produce bioethanol (Gabhane et al. 2014), cellulose microfibers (Elanthikkal et al. 2010) and laminated particle board (Baharin et al. 2016). Basically, particle board is a panel product manufactured from lignocellulosic materials, primarily in the form of discrete particles, combined with a synthetic resin or other suitable binder and bonded together under heat and pressure (US EPA 2002). Traditionally, particle board has been made from wood-based fibers bound together using a formaldehyde resin. Natural flax fibers have been used in Europe while hemp, jute, ramie, sisal and kenaf have been of interest in Asia (Pickering et al. 2007). Field crop residues like cereal straw, corn stalk, flax straw, corn cob, rice husk, husks coconut and peanuts represent a potentially valuable source of fiber which can be used as a supplement or substitute for wood fiber in the manufacture of composites such as particle board (Panthapulakkal et al. 2006, Yang et al. 2007). Factorial design is employed to determine the effect of each factor and interaction influence on the response of an experiment, reducing the number of runs, time and cost with the aim of obtaining the best response (Elhalil et al.
2016). In contrast, response surface methodology (RSM) is an effective tool that allows studying several factors and optimize multiple responses simultaneously through the conversion of estimated response models into a composite function and using the desirability function approach (Costa et al. 2011, Hashad et al. 2016). These methods have been applied to determine the influence of thrust force in the drilling process of medium density fiberboard (MDF) composite panels (Valarmathi et al. 2012).

This study attempts to apply full factorial design and RSM to determine the effect of pressing temperature and resin content on density, moisture, water absorption, water swelling, module of rupture (MOR), module of elasticity (MOE) and formaldehyde emission of a particle board made of banana pseudo-stem to provide an alternative material for the particle board industry.

\section{MATERIALS AND METHODS}

\section{MATERIALS AND REAGENTS}

Banana pseudo-stem was collected from El Oro, Ecuador. It was cut into layers of approximately 9 centimetres. It is important to mention that the floral stem was not part of this study. For initial drying, a rude mill used for grinding called "trapiche" was used. After that, the pseudo-stem was dehydrated in a tray dryer (unbranded) for 6 hours. For the milling of banana pseudo-stem fibers, we used a hammer mill (unbranded) which had a cyclone for separating the fine fiber (FF) and coarse fiber (CF).

Additionally, urea formaldehyde (UF) resin (CR-70 FL. 64-66\% solid content) and paraffin (Merk-1.11609.9025) were used as the adhesives and additives for making the particle boards.

\section{EXPERIMENT DESIGN}

The milled fibers were distributed on the sandwich particle board with fine fiber (FF) on the face layers and coarse fiber (CF) on the core layer according to a $2^{\mathrm{k}}$ factorial design (Table I). Resin and fiber were 
mixed thoroughly with the urea-formaldehyde resin CR-70 FL (Solid content: 64-66\%, Viscosity: 200-270 mPa.s, pH (25 ${ }^{\circ}$ ):7.9-8.1) and paraffin. The material was put in a stainless-steel mould, where it was pressed in a hydraulic press (Mega, 30 tons). Afterward, samples were conditionate at $20^{\circ} \mathrm{C} \pm 2{ }^{\circ} \mathrm{C}$ and $65 \% \pm 5 \%$ of relative humidity until constant mass was obtained. The fine fiber and coarse fiber from banana pseudo-stem and particle board developed are shown in Figure 1.

Also, a $2^{k}$ factorial design was performed to determine the operation conditions of board pressing. Hence, the factors or variables controllable by the experimenter $(\mathrm{k})$ were temperature $(\mathrm{T})$ and resin content (RC). The levels are shown in Table I as well fixed variables: pressure $\left(50 \mathrm{Kg} . \mathrm{cm}^{-2}\right.$ for $10 \mathrm{~min} ; 100 \mathrm{Kg} \cdot \mathrm{cm}^{-2}$ for $10 \mathrm{~min}$ ), paraffin $10 \%$, fiber ratio (CF: 45\%, FF :55\%), time (20 min.). The factorial design was performed with the statistic software Statgraphics Centurion XV and the combinations were configured in two blocks (Table I).

\section{PARTICLE BOARD EVALUATION}

\section{Physical properties}

Particle boards were cut into square of $25 \mathrm{~cm}^{2}$ to determine density (D) and moisture (M). Physical properties were tested according to the Colombian technical standard (NTC) 2261.

\section{Mechanical properties}

Bending strength (Module of rupture (MOR)) and elasticity (MOE) test were measured following the procedure of the "Comisión Venezolana de Normas Industriales" (COVENIN) 847-91. Briefly, a load was applied at the centre of the tested specimens at a material resistance equipment (Soiltest) supplied with a device to measure the load applied and deflection, until the maximum load was reached. The crosshead speed of the load was set at 9 $\mathrm{mm} \cdot \mathrm{min}^{-1}$. The MOR was calculated according to the Equation (Eq.) 1.

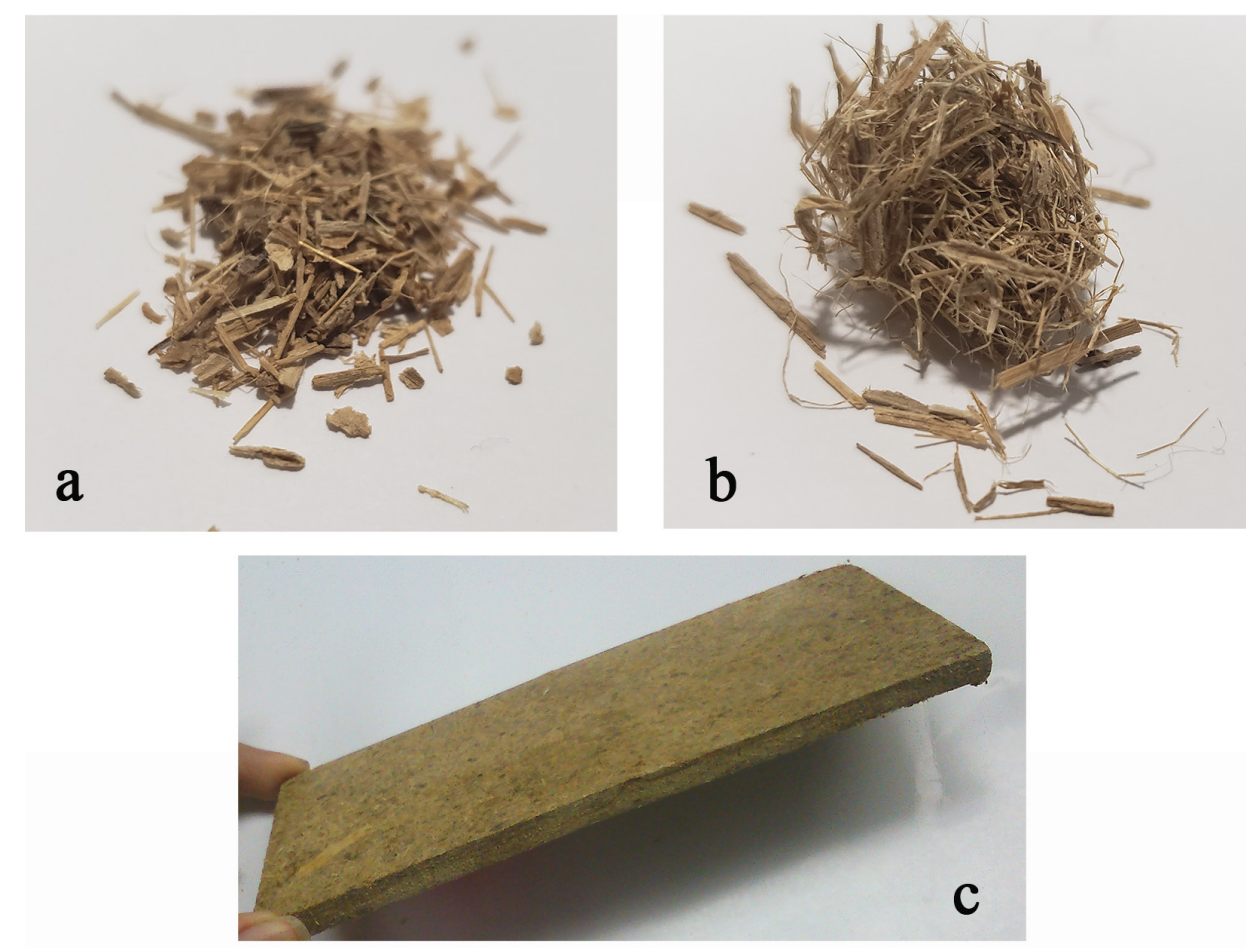

Figure 1 - Pictures of fine fiber (a), coarse fiber (b) and particle board made of banana pseudostem (c). 
$M O R=\frac{3 x P x L}{2 X a X e^{2}}$

Where "P" was the applied load (N), "L" distance between supports ( $\mathrm{mm})$, "a" the width of the specimen $(\mathrm{mm})$ and "e" nominal thickness of the specimen $(\mathrm{mm})$.

The module of elasticity was calculated by Eq. (2).

$$
M O E=\frac{P_{1} L^{3}}{4 X a X e^{3} X y_{1}}
$$

Where "P1" is the proportional limit load $(\mathrm{N})$, " $\mathrm{y}_{1}$ " the deflection in the proportional limit (mm), "e" nominal thickness of the specimen ( $\mathrm{mm})$, "a" width of the specimen $(\mathrm{mm})$ and "L" distance between the supports (mm).

\section{Water absorption and thickness swell properties}

As the test pieces had a square area of $25 \mathrm{~cm}^{2}$, the particle boards were soaked in water $(\mathrm{pH} 6 \pm 1$ ) for 2 hours. Board thickness and weight were measured before and after the immersion following the NTC 2261 standard.

\section{Formaldehyde content}

The formaldehyde captured from particle board $\left(25 \mathrm{~cm}^{2}\right)$ was developed following the methodology described in JIS 1460 (JIS 2001). The quantification of formaldehyde absorbed by water was determined using the methodology described by Soman (Soman et al. 2008) which indicated that formaldehyde reacts with 2.4-dinitrophenylhydrazine to form Schiff base. Thus it, can be measured in a high-performance liquid chromatography (HPLC) Perkin Elmer with diode array detector (DAD).

\section{OPTIMIZATION OF RESPONSES}

The optimization process was performed in the statistical program Statgraphics Centurion XV by response surface methodology. This method
TABLE I

Range and level of factors used in two-level factorial design to produce particle board.

\begin{tabular}{cccc}
\hline Factors & \multicolumn{2}{c}{ Range and level } & Unit \\
\hline \multirow{3}{*}{ Resin } & Low (-1) & High (+1) & \\
\cline { 2 - 3 } & $15 \mathrm{CF} ;$ & $25 \mathrm{CF} ;$ & \\
\multirow{2}{*}{ Temperature } & $35 \mathrm{FF}$ & $45 \mathrm{FF}$ & \\
\hline
\end{tabular}

establishes statistical relationship between factors and the evaluated properties, where the optimal conditions could be predicted to achieve the optimal board properties.

\section{RESULTS AND DISCUSSION}

The cutting and drying process of banana pseudostem $(27.22 \pm 7.19 \mathrm{Kg})$ obtained a total yield of 4.52 $\%$ from available raw material $(1.22 \pm 0.49 \mathrm{Kg})$ to produce particle board, with an average thickness of $0.87 \pm 0.07 \mathrm{~cm}$. Moreover, the experimental $2^{\mathrm{k}}$ factorial design which yielded a total of 8 runs in a random order and the response for the properties evaluated are presented in Table II. Therefore, factorial experiments permit to evaluate the combined effect of experimental variables $(\mathrm{RC}, \mathrm{T})$ when used simultaneously (Winer et al. 1991).

\section{MODEL FITTING}

The optimization of production process of fiberboards was performed using a first order model, where WS, D, FC, MOR, MOE, and WA $\left(\mathrm{R}^{2}\right.$ : 98.99 , $92.66,95.40,91.89,90.02,90.90 \%)$ showed a good percentage of the experimental data variation this is explained by the model which is represented by an $\mathrm{R}^{2}$ value higher than $80 \%$ (Karazhiyan et al. 2011) except from moisture content on fiberboards that demonstrated a high variation around the mean $\left(\mathrm{R}^{2}\right.$ : $72.52 \%)$.

\section{Effect of resin and temperature on density}

Density value (D) classifies particle boards into high $(\mathrm{D}>0.8)$, medium $(0.5<\mathrm{D}<0.8)$, and low density $(\mathrm{D}<0.5)$. According to Table II, only the 
TABLE II

Experimental design layout and mechanical, physical and chemical properties of fiber boards.

\begin{tabular}{|c|c|c|c|c|c|c|c|c|c|}
\hline Run & RC & $\mathbf{T}$ & $\begin{array}{l}\text { Density } \\
\left({\left.\mathrm{g} . \mathrm{cm}^{-3}\right)}^{-}\right.\end{array}$ & $\begin{array}{c}\text { Moisture } \\
\text { (\%) }\end{array}$ & $\begin{array}{c}\text { Water } \\
\text { absorption } \\
(\%)\end{array}$ & $\begin{array}{c}\text { Water } \\
\text { swelling }(\%)\end{array}$ & $\begin{array}{c}\text { MOR } \\
\left(\text { N.mm }{ }^{-2}\right)\end{array}$ & $\begin{array}{c}\text { MOE } \\
(\text { N.mm } \\
\text { (-2) }\end{array}$ & $\begin{array}{c}\text { FC } \\
(\mathrm{mg} / 100 \mathrm{~g})\end{array}$ \\
\hline F1 & 1 & -1 & 0.864 & 2.281 & 5.224 & 4.179 & 28.414 & 4006.569 & 1.577 \\
\hline F2 & 1 & 1 & 0.842 & 1.837 & 14.542 & 4.615 & 45.238 & 7740.905 & 6.282 \\
\hline F3 & -1 & -1 & 0.985 & 3.179 & 10.852 & 8.615 & 25.996 & 3521.872 & 1.865 \\
\hline F4 & -1 & 1 & 0.885 & 2.579 & 6.287 & 8.320 & 47.062 & 3074.771 & 1.045 \\
\hline F5 & -1 & -1 & 0.924 & 3.227 & 8.376 & 9.312 & 27.106 & 3820.713 & 1.015 \\
\hline F6 & 1 & -1 & 0.846 & 3.989 & 8.026 & 5.809 & 33.917 & 3192.499 & 1.458 \\
\hline F7 & -1 & 1 & 0.901 & 2.610 & 8.573 & 9.392 & 51.018 & 2467.568 & 1.651 \\
\hline F8 & 1 & 1 & 0.799 & 1.800 & 19.106 & 5.179 & 37.304 & 5295.171 & 4.788 \\
\hline
\end{tabular}

TABLE III

ANOVA analysis from response data.

\begin{tabular}{cccccccc}
\hline & Density & Moisture & $\begin{array}{c}\text { Water } \\
\text { absorption }\end{array}$ & $\begin{array}{c}\text { Water } \\
\text { swelling }\end{array}$ & MOR & MOE & $\begin{array}{c}\text { Formaldehyde } \\
\text { content }\end{array}$ \\
\hline $\mathrm{X}_{0}$ & $0.88102 *$ & $2.688^{*}$ & $10.123^{*}$ & $6.928^{*}$ & $37.01^{*}$ & $4140^{*}$ & $2.460^{*}$ \\
$\mathrm{X}_{1}$ & $-0.04282 *$ & -0.211 & 1.601 & $-1.982^{*}$ & -0.79 & $919^{*}$ & $1.066^{*}$ \\
$\mathrm{X}_{2}$ & -0.02385 & -0.481 & 2.004 & -0.051 & $8.15^{*}$ & 505 & $0.981 *$ \\
$\mathrm{X}_{12}$ & 0.00678 & -0.177 & $3.096^{*}$ & 0.003 & -3.10 & $955^{*}$ & $1.027 *$ \\
$\mathrm{R}^{2}$ & $92.66 \%$ & $72.52 \%$ & $90.90 \%$ & $98.99 \%$ & $91.89 \%$ & $90.02 \%$ & $95.40 \%$ \\
\hline
\end{tabular}

$\mathrm{X}_{1}=$ Resin content $(\%), \mathrm{X}_{2}=$ Temperature $\left({ }^{\circ} \mathrm{C}\right), \mathrm{MOR}=$ Module of rupture $\left(\mathrm{N} \cdot \mathrm{mm}^{-2}\right), \mathrm{MOE}=$ Module of elasticity $\left(\mathrm{N} \cdot \mathrm{mm}^{-2}\right), \mathrm{FC}=$ Formaldehyde content $(\mathrm{mg} / 100 \mathrm{~g}), \mathrm{R}^{2}=$ Coefficient of determination. Level of significance $* \mathrm{p}<0.05$.

particle board from run 8 corresponds to medium density, whereas the others correspond to a high board (Ye et al. 2007).

Therefore, the model is fitted with good prediction $\left(\mathrm{R}^{2}=92.66 \%\right)$. Linear effect of resin content $\left(\mathrm{X}_{1}\right)$ showed significant effect on density. Besides, no significant interaction between temperature and UF-resin on average density was observed (Table III). Average density and UF- resin intensely influenced the mechanical properties of particleboards. When values of density increased, MOR and MOE values increased, the thickness swelling and water absorption decreased (Halvarsson et al. 2008). As content of resin increased, density value decreased (Fig. 2a). However, a positive relationship between resin and density has been reported (Arabi et al. 2011). Further studies should be performed to determine if particle size of banana pseudo-stem cause an inverse relationship between density and resin.

Density $=0.88102-0.04282$ Resin $(\%)-0.02385$ Temperature $\left({ }^{\circ} \mathrm{C}\right)$

+0.00678 Resin $(\%) *$ Temperature $\left({ }^{\circ} \mathrm{C}\right)$

\section{Effect of resin and temperature on moisture}

The model does not demonstrate significant $(p<0.05)$ value with none of the factors $\left(X_{1} . X_{2}\right)$ and the interactions of them $\left(\mathrm{X}_{1,2}\right)$. Besides the variation of the responds is poor explained by the model $\left(\mathrm{R}^{2}\right.$ : 72. 52\%). Hence, the used factor might not affect strongly the property value. This, behaviour could be explained by the percentage of paraffin as it was a constant value. Incidentally, it was a waterproofing agent acting as a barrier between the pore spaces in the fibers (Beijing Institute of Technology 2016). 


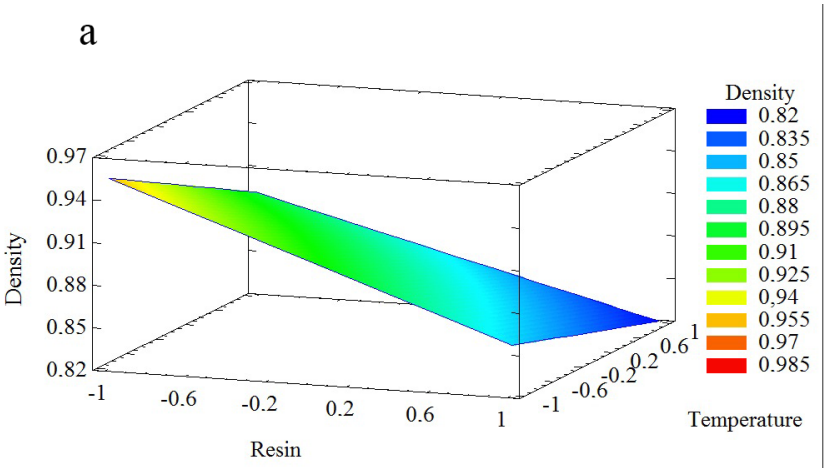

$\mathrm{b}$

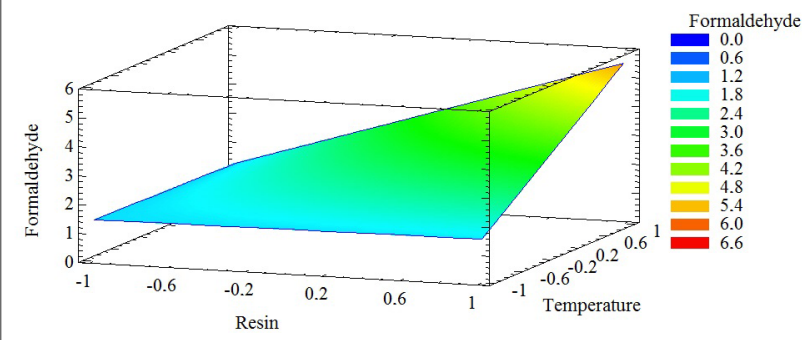

$\mathrm{C}$
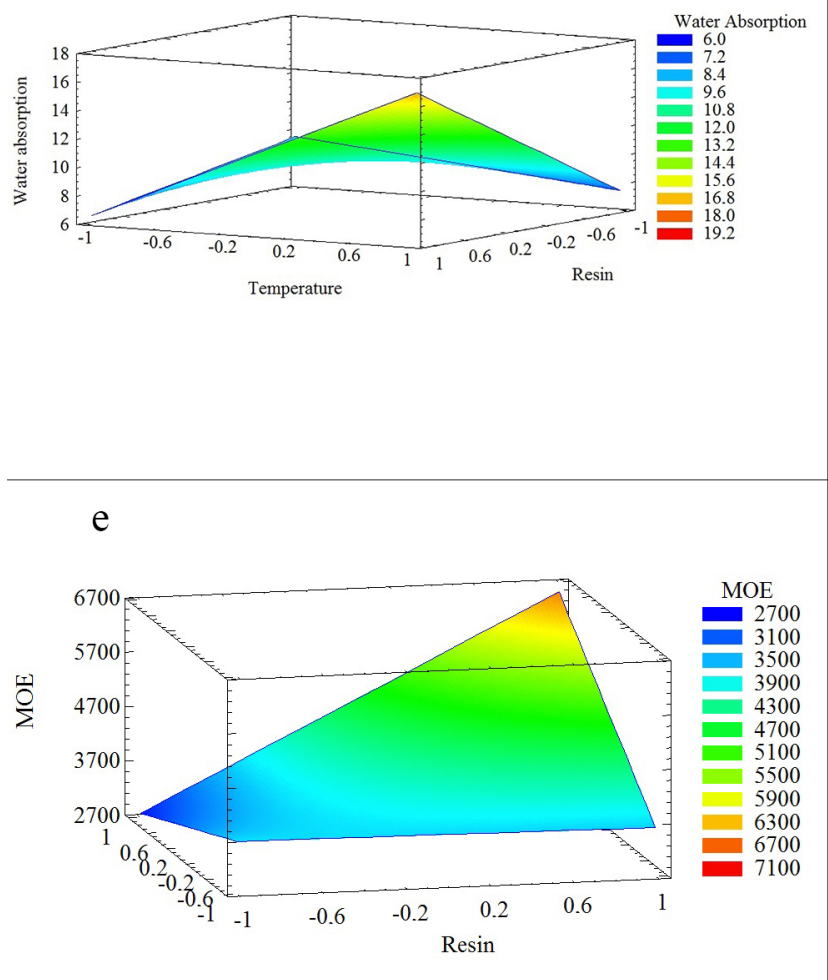

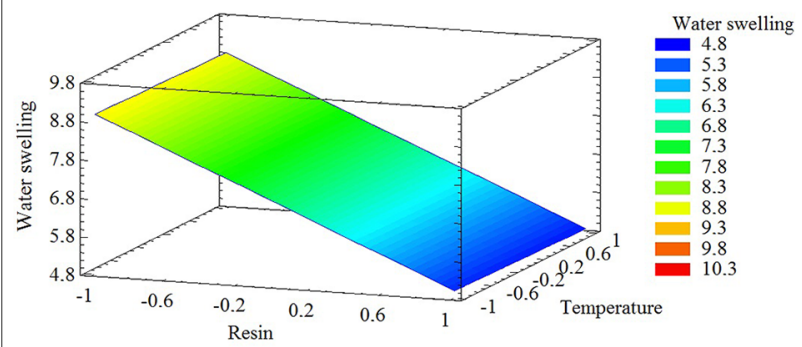

d

\section{f}

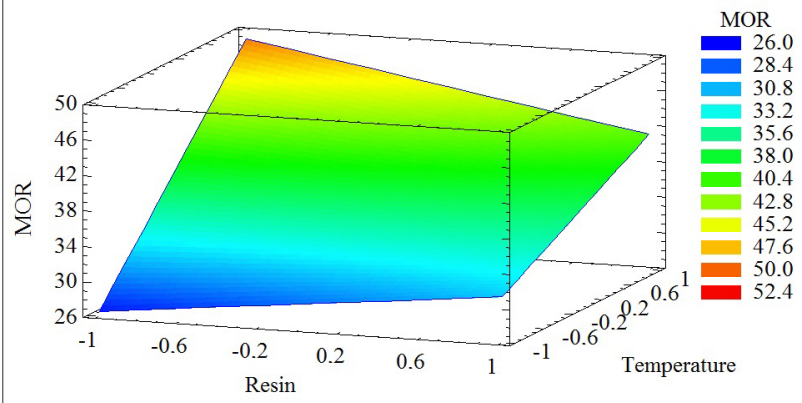

Figure 2 - Interaction effect of resin and temperature on (a) density, (b) FC, (c) WA, (d) WS, (e) MOE, (f) MOR.

Effect of resin and temperature on formaldehyde content

Formaldehyde emission response are shown in Table II where all values are below the maximum limit of $30 \mathrm{mg} / 100 \mathrm{~g}$ (NTC 2261). Response surface graph (Figure 2b) and the equation system shows a positive influence of the resin, temperature and the interaction of them at the formaldehyde emission, similar behaviour reported by Petinarakis (Petinarakis and Kavvouras 2006) who stated that with increasing temperature the formaldehyde 
emission increases in the board; phenomenon can be explained by the thermal degradation of the resin (Szesztay et al. 1993). As the resin content is reported as Christensen (Christensen et al. 1981) that the formaldehyde emission increases approximately linearly when the resin content increases.

Formaldehyde content $=2.460+1.066$ Resin $(\%)$ +0.981 Temperature $\left({ }^{\circ} \mathrm{C}\right)$

+1.027 Resin $(\%) *$ Temperature $\left({ }^{\circ} \mathrm{C}\right)$

\section{Effect of resin and temperature on water} absorption

The water absorption percentage $(2 \mathrm{~h})$ of the test samples is shown in Table II. When comparing the data obtained with the standard (COVENIN 847-91) we observed that all values are within the allowable limit (Max. 25\%). Thus, at the response surface graphic (Figure 2c) and the equation for water absorption indicate that increasing resin and temperature values in the model show an increase in the property value. Although, literature indicates that the resin improves the absorption properties (Panthapulakkal et al. 2006), in this case the increasing resin decreased absorption properties. Moreover, the temperature increases as the percentage of water absorption increases. These results are similar to those of Winandyt who states that the increased time and pressing temperature do not inhibit the ability of the panels to absorb water (Winandyt and Krzysik 2007).

Therefore, the interaction between the resin content and temperature $(\mathrm{p}<0.05)$ has an influence on the response variable. Linear relationship (correlation) between the property and independent variable shows a good correlation $\left(\mathrm{R}^{2}\right.$ : $\left.90.90 \%\right)$.

Water absorption $=10.123+1.601$ Resin $(\%)+$ 2.004 Temperature $\left({ }^{\circ} \mathrm{C}\right)$

$+3.096 \operatorname{Resin}(\%) *$ Temperature $\left({ }^{\circ} \mathrm{C}\right)$
Effect of resin and temperature on water swelling

Water swelling results reported in Table II show that four values do not meet the maximum range of $6 \%$ for the COVENIN 847-91. This behaviour corresponds to all the formulations with low resin. It is important to observe, the relationship of the resin with swelling since it increases as the amount of resin decreases as mentioned in studies by Palardy (Palardy et al. 1989). Also, the relationship is reflected in response surfaces (Figure 2d) and at the fitted lineal equation represented as following:

Water swelling $=6.928-1.982$ Resin $(\%)$

- 0.051 Temperature $\left({ }^{\circ} \mathrm{C}\right)$

+0.003 Resin $(\%)^{*}$ Temperature $\left({ }^{\circ} \mathrm{C}\right)$

The temperature and the interaction with resin did not show significant effect on water swelling. However, the resin influence $(p<0.001)$ on the water swelling and it has a negative effect on the value.

Effect of resin and temperature on elastic modulus

Design responses for MOE are exposed in Table II, where all values are within the minimum accepted range 2400 N.mm ${ }^{-2}$ under the NTC 2261 standard.

Resin content and the interaction with temperature demonstrate a significant $(p<0.05)$ effect on module of elasticity. Moreover, the temperature not affect the response of the experiment. Response surface graphic (Figure 2e) and the equation below shows that the module of elasticity increases proportionally to the resin content. This coincides with similar results of Malanit (Malanit 2009) who attributes the improvement of stiffness of particle board to the resin content.

$\mathrm{MOE}=4140+919 \operatorname{Resin}(\%)$

+505 Temperature $\left({ }^{\circ} \mathrm{C}\right)$

+ 955 Resin $(\%) *$ Temperature $\left({ }^{\circ} \mathrm{C}\right)$ 


\section{Effect of resin and temperature on modulus of} rupture

Module of rupture results are exposed on Table II where all the values are on the minimum accepted range of 21 N.mm ${ }^{-2}$ stablish by the NTC 2261 standard. The response surface graph (Figure 2f) and the equation described below show the proportional relation of the resin and temperature with the MOR where the temperature relation is less predominant. This coincides with the results informed by Iswanto. The author reported that while the pressing temperature increases, the MOR value grows (Iswanto et al. 2014). Similarly, Post indicated that the resin content has only a slight effect on the modulus of rupture studies (Post 1958). Furthermore, Halvarsson described that the amount of added resin, type of resin, storage time, and type of straw pre-treatment (water or acid) had no major effect on the bending properties (Halvarsson et al. 2008). Furthermore, Maloney explained that one of the factors influencing the MOR value is the geometry of the particles (Maloney 1993).

$\mathrm{MOR}=37.01-0.79 \mathrm{Resin}(\%)+8.15$

Temperature $\left({ }^{\circ} \mathrm{C}\right)-3.10$ Resin $(\%) *$ Temperature

$\left({ }^{\circ} \mathrm{C}\right)$
The temperature has a positive significant influence $(\mathrm{p}<0.05)$. However, resin $\left(\mathrm{X}_{1}\right)$ and the interaction of factor $\left(\mathrm{X}_{1,2}\right)$ did not demonstrate a significant influence on the property.

\section{Load and displacement relationship}

In order to calculate the MOR value the maximum strength of the boards were measured, while the MOE indicates the rigidity of the material when subjected to a certain stress (resistance to deformation under tension) and is related to the proportional limit load (N). The curve of load applied and the displacement of the particle board is shown at the Figure 3, at all curves there are three regions or different behaviours. The first one correspond to the linear tendency which is related to the elastic behaviour of the particle board (MOE), the next stage when the slope is less pronounced and the final stage is when it visualised a horizontal line or " 0 " slope which it's when the material begins to fracture. This last force is used to calculate the module of rupture.

The Figure 3 shows that the particle board that had the highest load at the linear stage is the F7 ( RC (-1), T (1)) that is not the same behaviour that the results of the MOE value. These is explained because not all fiber boards had the same thickness

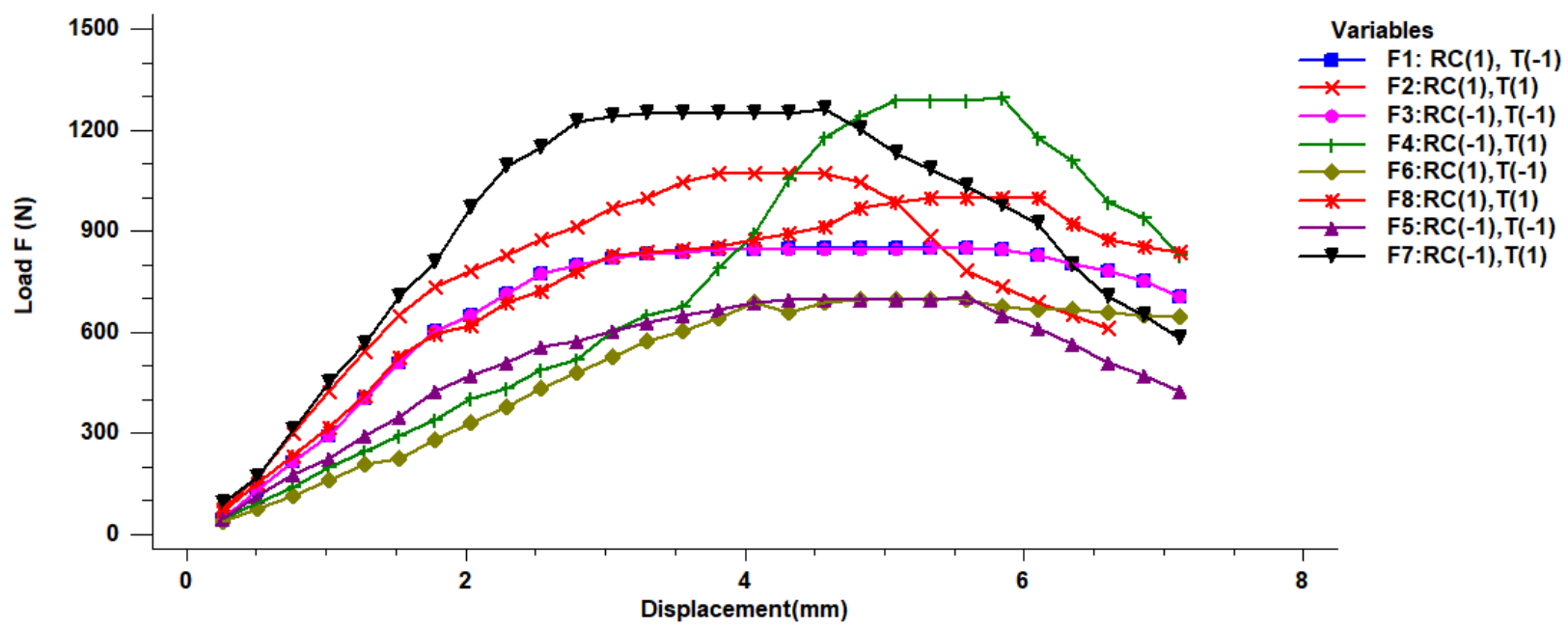

Figure 3 - Load and displacement relationship of particle boards. 
and displacement, factors that are validated on the MOE equation. The figure explained the maximum force that can be applied against the boards and it maintained an elastic behaviour.

By the other hand, the maximum force before the rupture is represented by the $\mathrm{F} 4(\mathrm{RC}(-1), \mathrm{T}(1))$ similar results are shown at the MOR values. The results presented depends of the use of fiber boards. It means that in a furniture application where there are continues loads it is preferred to use a board with the highest range of elastic behaviour with an accepted MOR value.

\section{Multiple Response Optimization}

Statistical software Statgraphics Centurion XV was used to determine the combination of experimental factors that simultaneously optimizes the goal of each property (Table IV).

The response surface method is used to find the combination of factors for optimum global desirability. The factors that optimize the response are 0.711385 for resin content $(43.15 \% \mathrm{FF}$, $23.97 \% \mathrm{CF}$ ) and 0.261366 for pressing temperature $\left(162.61{ }^{\circ} \mathrm{C}\right)$ with a global desirability of 0.816684 (Figure 4). In Table V, the optimized temperature and resin content predict new expected responses, where all properties meet quality standards.

\section{CONCLUSIONS}

This work is a contribution to the general problem of the agriculture waste, the properties evaluated at the fiber boards will serve as a base to future research that might be applied to industry. The results of this study demonstrate that banana pseudo-stem can be used as raw material to produce particle boards. The boards met all quality parameters except ones with low resin content that didn't meet WS parameter and the process conditions were optimized to $162.61{ }^{\circ} \mathrm{C}$ and $43.15 \% \mathrm{FF}, 23.97 \% \mathrm{CF}$. Furthermore, full factorial design and RSM demonstrate the relation of factors with the response data.

TABLE IV

Property optimization goals.

\begin{tabular}{cccc}
\hline & Desirability & Desirability & \\
\hline Property & Low & High & Goal \\
Water absorption & 5.0 & 19.0 & 12.5 \\
Density & 0.79 & 0.98 & 0.85 \\
Formaldehyde emission & 1.0 & 6.0 & Minimize \\
Water swelling & 4.0 & 9.0 & Minimize \\
MOE & 2467.0 & 7740.0 & 5103.0 \\
MOR & 25.0 & 51.0 & 38.0 \\
\hline
\end{tabular}

TABLE V

Predicted response data.

\begin{tabular}{cccc}
\hline Response & Optimal value & Standard value & Standard \\
\hline Density & 0.845 & $>0.8{\mathrm{~g} . \mathrm{cm}^{-3}}^{-3}$ & NTC 2261 \\
Water absorption & 12.361 & Max. $25 \%$ & NTC 2261 \\
Water swelling & 5.505 & Max. $6 \%$ & NTC 2261 \\
MOE & 5103.0 & $2400 \mathrm{~N} . \mathrm{mm}^{-2}$ & COVENIN $847-91$ \\
MOR & 38.0 & Min. $21 \mathrm{~N} \cdot \mathrm{mm}^{-2}$ & COVENIN $847-91$ \\
Formaldehyde emission & 3.666 & $30 \mathrm{mg} .100 \mathrm{~g}^{-1}$ & NTC 2261 \\
\hline
\end{tabular}




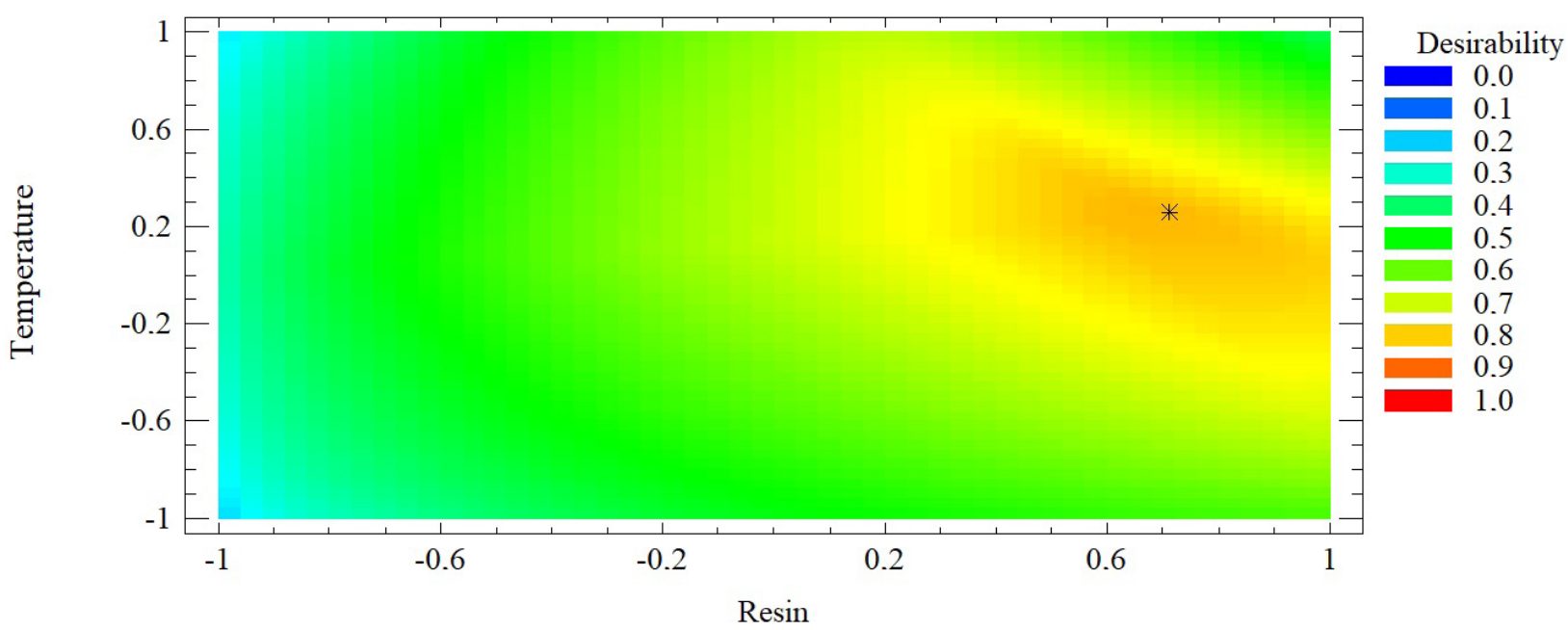

Figure 4 - Optimization of global desirability.

Future research should be directed at conducting studies on the effect of the morphological distribution of fibers on their mechanical and physical properties. And also the control of variables must be improve in the case of the thickness of the boards.

\section{ACKNOWLEDGMENTS}

The authors thank the Escuela Superior Politécnica del Litoral and the Universidad Laica Vicente Rocafuerte for support of this study. This research study is part of the cooperation agreement between both institutions in the framework of the project No. CIBE-2014-14 titled "Desarrollo de productos a partir de residuos y excedentes agroindustriales con potencial uso en la industria y medicina"

\section{AUTHOR CONTRIBUTIONS}

Ana Barragan-Lucas and Cristhian LlerenaMiranda participated actively together in the theoretical framework, experimental analysis, discussion of results and analyzed the data. Maria Fernanda Quijano-Avilés and Iván ChóezGuaranda designed the experiments, contributed to the interpretation of the results and prepared figures and tables. Linda Maldonado-Guerrero and Patricia Manzano Santana were involved in planning and supervised the work.

\section{REFERENCES}

ARABI M, FAEZIPOUR M AND GHOLIZADEH H. 2011. Reducing resin content and board density without adversely affecting the mechanical properties of particleboard through controlling particle size. J For Res 22(4): 659664.

BAHARIN A, FATTAH N, BAKAR A AND ARIFF Z. 2016. Production of Laminated Natural Fibre Board from Banana Tree Wastes. Procedia Chem 19: 999-1006.

BEIJING INSTITUTE OF TECHNOLOGY. 2016. SRD CODE: 5225 Production Technology of New fiberboard MDF waterproofing agent (Technology) - SRD Pacific China Venture Services.

CASSIDY A, HUANG T, RICE M, RIMM E AND TWOROGER S. 2014. Intake of dietary flavonoids and risk of epithelial ovarian cancer. Am J Clin Nutr 100(5): 1344-1351.

CHRISTENSEN R, ROBITSCHEK P AND STONE J. 1981. Formaldehyde emission from particleboard. Eur J Wood Wood Prod 39(6): 231-234.

COSTA N, LOURENÇO J AND PEREIRA Z. 2011. Desirability function approach: A review and performance evaluation in adverse conditions. Chemom Intell Lab Syst 107(2): 234-244.

ELANTHIKKAL S, GOPALAKRISHNAPANICKER U, VARGHESE S AND GUTHRIE J. 2010. Cellulose microfibres produced from banana plant wastes: Isolation and characterization. Carbohydr Polym 80(3): 852-859.

ELHALILA, TOUNSADI H, ELMOUBARKI R, MAHJOUBI F, FARNANE M, SADIQ M AND BARKA N. 2016. Factorial experimental design for the optimization of catalytic degradation of malachite green dye in aqueous solution by Fenton process. Water Resour Ind 15: 41-48.

FAO - FOOD AND AGRICULTURE ORGANIZATION. 2017. Banana facts and figures. Retrieved March 20, 2018, 
from http://www.fao.org/economic/est/est-commodities/ bananas/bananafacts/en/\#.WrFseKhuZPZ

GABHANE J, WILLIAM S, GADHE A, RATH R, VAIDYAA AND WATE S. 2014. Pretreatment of banana agricultural waste for bio-ethanol production: individual and interactive effects of acid and alkali pretreatments with autoclaving, microwave heating and ultrasonication. Waste Manag 34(2): 498-503.

HALVARSSON S, EDLUND H AND NORGREN M. 2008. Properties of medium-density fibreboard (MDF) based on wheat straw and melamine modified urea formaldehyde (UMF) resin. Ind Crops Prod 28(1): 37-46.

HASHAD R, ISHAK R, GENEIDI A AND MANSOUR S. 2016. Methotrexate loading in chitosan nanoparticles at a novel $\mathrm{pH}$ : Response surface modeling, optimization and characterization. Int J Biol Macromol 91: 630-639.

HO L, ABDUL AZIZ N AND AZAHARI B. 2013. Physicochemical characteristics and sensory evaluation of wheat bread partially substituted with banana (Musa acuminata $\mathrm{X}$ balbisiana cv. Awak) pseudo-stem flour. Food Chem 139(1-4): 532-539.

ISWANTO A, AZHAR I AND SUSILOWATI A. 2014. Effect of resin type, pressing temperature and time on particleboard properties made from sorghum bagasse. Agric For Fish 3(2): 62-66.

JIS A 1460. 2001. Building boards Determination of formaldehyde emission Desicator method.

KARAZHIYAN H, RAZAVI S AND PHILLIPS G. 2011. Extraction optimization of a hydrocolloid extract from cress seed (Lepidium sativum) using response surface methodology. Food Hydrocoll 25(5): 915-920.

MALANIT P. 2009. The Suitability of Dendrocalamus asper Backer for Oriented Strand Lumber. University of Hamburg.

MALONEY T. 1993. Modern particleboard \&amp; dryprocess fiberboard manufacturing. Madison: Forest Products Society 1: 681 .

PALARDY R, HAATAJA B, SHALER S AND WILLIAMS A. 1989. Pressing of wood composite panels at moderate temperature and high moisture content. Forest products 39(4): 27-32.

PANTHAPULAKKAL S, ZERESHKIAN A AND SAIN M. 2006. Preparation and characterization of wheat straw fibers for reinforcing application in injection molded thermoplastic composites. Bioresour Technol 97(2): 265272.

PEREIRA A, NASCIMENTO D, SOUZA FILHO M, MORAIS J, VASCONCELOS N, FEITOSA J AND ROSA M. 2014. Improvement of polyvinyl alcohol properties by adding nanocrystalline cellulose isolated from banana pseudostems. Carbohydr Polym 112: 165-172.
PETINARAKIS J AND KAVVOURAS P. 2006. Technological factors affecting the emission of formaldehyde from particleboards. Wood Res 51(1): 31-40.

PICKERING K, BECKERMANN G, ALAM S AND FOREMAN N. 2007. Optimising industrial hemp fibre for composites. Compos Part A Appl Sci Manuf 38(2): 461-468.

POST P. 1958. Effect of particle geometry and resin content on bending strength of oak flakeboard. Forest Prod J 8(10): 317-322.

PRO ECUADOR. 2015. Banano y plátano. Recovered from: http://www.proecuador.gob.ec/compradores/ofertaexportable/banano/. Accessed: 18/08/2016.

QUINTANA G, VELÁSQUEZ J, BETANCOURT S AND GAÑÁN P. 2009. Binderless fiberboard from steam exploded banana bunch. Ind Crops Prod 29(1): 60-66.

SHAH M, REDDY G, BANERJEE R, RAVINDRA BABU P AND KOTHARI I. 2005. Microbial degradation of banana waste under solid state bioprocessing using two lignocellulolytic fungi (Phylosticta spp. MPS-001 and Aspergillus spp. MPS-002). Process Biochem 40(1): 445451.

SOMAN A, QIU Y AND CHAN LI Q. 2008. HPLC-UV Method Development and Validation for the Determination of Low Level Formaldehyde in a Drug Substance. J Chromatogr Sci 46: 461-465.

SZESZTAY M, LÁSZLÓ-HEDVIG Z, KOVACSOVICS E AND TÜDÖS F. 1993. DSC application for characterization of Urea/formaldehyde condensates. Eur J Wood Wood Prod 51(5): 297-300.

US EPA - UNITED STATES ENVIRONMENTAL PROTECTION AGENCY. 2002. Wood Products Industry. https://www3.epa.gov/ttnchie1/old/ap42/ch10/s062/ c10s06-2.pdf. 2002. Wood Products Industry.

VALARMATHI T, PALANIKUMAR K AND SEKAR S. 2012. Modeling of Thrust Force in Drilling of Plain Medium Density Fiberboard (MDF) Composite Panels Using RSM. Procedia Eng 38: 1828-1835.

WINANDYT J AND KRZYSIK A. 2007. Thermal degradation of wood fibers during hot-pressing of mdf composites: part 1. relative effects and benefits of thermal exposure. Wood fiber Sci 39(3): 450-461.

WINER B, BROWN D AND MICHELS K. 1991. Statistical principles in experimental design. McGraw-Hill.

YANG H, KIM H, PARK H, LEE B AND HWANG T. 2007. Effect of compatibilizing agents on rice-husk flour reinforced polypropylene composites. Compos Struct 77(1): 45-55.

YE X, JULSON J, KUO M, WOMAC A AND MYERS D. 2007. Properties of medium density fiberboards made from renewable biomass. Bioresour Technol 98(5): 1077-1084. 